\title{
A DIPLOMÁTICA CONTEMPORÂNEA: REFLEXÕES SOBRE SUA APLICABILIDADE NA ERA DIGITAL
}

\section{LA DIPLOMÁTICA CONTEMPORÁNEA: REFLEXIONES SOBRE SU APLICABILIDAD EN LA ERA DIGITAL}

William Silva ${ }^{a}$

Daniel Flores ${ }^{b}$

\begin{abstract}
RESUMO
Introdução: Ao longo de muito tempo, a Diplomática contribuiu significativamente para a identificação da autenticidade dos documentos, ampliando seu rol de atuação quando foi influenciada por outras disciplinas, tais como a Arquivística moderna, que potencializou o seu objeto de estudo, mostrando a profunda ligação entre a espécie e sua atividade geradora. Objetivo: $O$ presente trabalho tem como objetivo realizar reflexões acerca da evolução da Diplomática Clássica para a Diplomática Contemporânea, a relação entre esta disciplina e a Classificação Documental e os seus impactos diante a era digital, na constituição do processo de autenticidade dos documentos arquivísticos digitais. Metodologia: A natureza pesquisa é classificada como básica, a forma de abordagem é classificada como qualitativa, o objetivo da pesquisa classificada como exploratória, envolvendo levantamento bibliográfico a respeito da diplomática na sua relação com a arquivística e a empregabilidade na era digital. Resultados: Após a pesquisa, compreende-se que a Diplomática perpassa os tempos, diante os aspectos de estudo da espécie documental, até o momento de sua relação com a Arquivística moderna, quando compreende o universo de estudo da Tipologia Documental, identificando-se com a Classificação, enquanto função matricial da Arquivística moderna, e utilizando dos recursos da análise da autenticidade no ambiente digital. Conclusão: É evidente que há uma relação intrínseca entre a Diplomática, em sua perspectiva contemporânea, com a Arquivística moderna, tanto na compreensão dos aspectos da tipologia documental, quanto como ferramenta essencial na análise da autenticidade no ambiente digital.
\end{abstract}

Descritores: Diplomática Contemporânea. Tipologia Documental. Classificação. Autenticidade. Documentos Arquivísticos Digitais.

\footnotetext{
a Mestre em Patrimônio Cultural pela Universidade Federal de Santa Maria - PPGPPC/UFSM. Professor do Instituto Federal de Educação, Ciência e Tecnologia do Rio Grande do Sul IFRS. E-mail: william.gontijo.@poa.ifrs.edu.br

b Doutor em Ciência da Informação pela Universidade Federal do Rio de Janeiro. Professor da Universidade Federal de Santa Maria. E-mail: dfloresbr@gmail.com
} 


\section{INTRODUÇÃO}

A Diplomática enquanto disciplina foi durante muitos séculos apresentada como aquela que conduziria o processo de identificação da autenticidade dos documentos.

Com forte influência de outras disciplinas, principalmente pela Arquivística moderna, que ampliava a percepção do documento, a Diplomática aprofunda em seu objeto de estudo e passa os variados tipos de documentos, que eram construídos a partir da junção da espécie documental e sua atividade geradora.

A classificação, como função matricial da Arquivística, passa a ver na Diplomática um grande ponto de apoio no trabalho de tratamento documental, garantindo que os elementos propostos pudessem ser aproveitados pela função.

Para discutir essa relação diante a era digital e os novos formatos de documentos, o presente trabalho buscou, por meio de um levantamento bibliográfico, referenciais teóricos da Arquivística e Diplomática, os diálogos sobre a relação existente entre a Diplomática Contemporânea e a Classificação diante o trabalho de tratamento e identificação da autenticidade dos documentos digitais.

A pesquisa foi dividida em quatro partes, sendo uma parte inicial falando sobre os momentos históricos do surgimento da Diplomática Contemporânea, a partir dos preceitos iniciais sobre a Diplomática Clássica. Na segunda parte realizando reflexões sobre a Diplomática e a Tipologia Documental, bem como a visão estreita com a arquivologia. $\mathrm{Na}$ terceira parte, tomando como base as reflexões realizadas sobre o objeto de estudo da Diplomática Contemporânea, qual a relação existente entre esta disciplina e a Classificação. Na quarta e última parte o trabalho explora o envolvimento da Diplomática Contemporânea nos documentos digitais, dando ênfase aos elementos essenciais na identificação da autenticidade e tratamento dos documentos digitais.

\section{DA DIPLOMÁTICA CLÁSSICA À DIPLOMÁTICA CONTEMPORÂNEA}

O documento, segundo retrata Heredia Herrera (1991), é objeto de atenção tanto da arquivística, quanto da Diplomática, da Paleografia, da Sigilografia e da História. 
Ao longo de vários anos a Diplomática possuiu um viés voltado para o estudo das características extrínsecas e intrínsecas dos documentos, com uma ênfase na estrutura formal dos documentos que eram ou não considerados autênticos, a partir dos elementos básicos que os compõem.

Já Rogers (2016) traduz a Diplomática como uma Ciência, e que foi desenvolvida durante os séculos XVII e XVIII com o objetivo de comprovar a autenticidade e, de forma indireta, a confiabilidade de documentos de arquivo, "(....) a fim de estabelecer a existência de direitos patrimoniais da igreja e suas ordens religiosas e outras autoridades, e para identificar e eliminar falsificações." (ROGERS, 2016, p.20)

Rogers (2016) ainda afirma que,

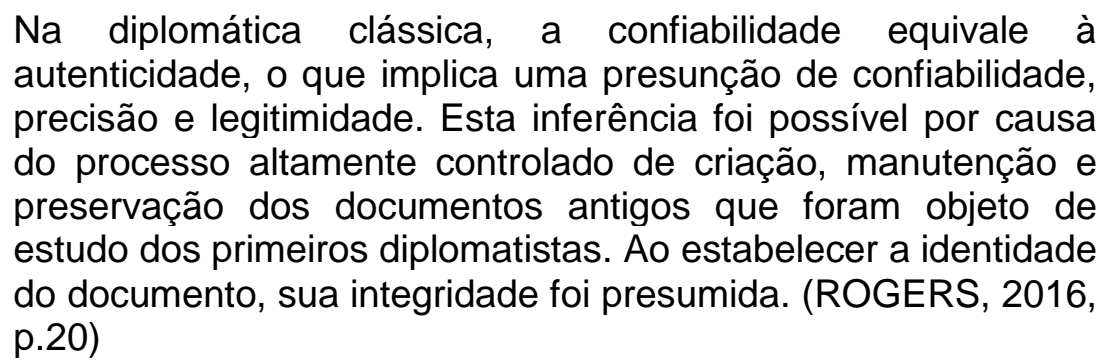

Segundo Tognoli e Guimarães (2009) a Diplomática nasce no século XVII, tendo como finalidade o estabelecimento de regras que pudesse comprovar a autenticidade de documentos produzidos pela Igreja, sendo que os primeiros volumes da Acta Sanctorum constituíram os primeiros documentos da Igreja Católica que foram separados para serem analisados se na vida dos santos haviam lendas ou não. A iniciativa, conforme elucida Tognoli e Guimarães (2009, p. 26), "partiu dos Bolandistas, que convidam o jesuíta Daniel Papenbroek para escrever a introdução do segundo volume da Acta".

Foi dessa forma que Papenbroek anunciou os primeiros princípios que estabeleciam a autenticidade de documentos antigos, aplicando-os aos documentos que estavam preservados no mosteiro de Sant-Denis. Essas ações geraram mais tarde uma grande repercussão no meio eclesiástico, denominado "guerras diplomáticas", ou bela diplomática, originando uma série de disciplinas que objetivavam o estabelecimento da autenticidade de documentos, tais como a Diplomática, a Paleografia e a Sigilografia. (TOGNOLI; GUIMARÃES, 2008) 
Jean Mabilon, monge beneditino, respondendo Papenbroek, publica um tratado intitulado De re diplomática libri VI, que foi estruturado em seis partes e que estabelecia regras precisas para verificar a autenticidade dos documentos, promulgando assim uma nova ciência, que seria conhecida como Diplomática". (TOGNOLI; GUIMARÃES, 2009, p.26)

O objetivo do método empregado por Mabilon era dividir o documento em partes e analisa-las de forma separada, verificando os elementos internos e externos, sendo disseminado por toda a Europa nas escolas de Direito, conforme elucida Tognoli e Guimarães (2009).

Segundo Duranti (2015) antigos diplomatistas compreenderam ações administrativas e funções que geravam documentos a partir da análise das formas documentais, por meio da criação de uma metodologia que permitisse identificar as semelhanças e diferenças que possibilitavam a concepção das formas documentais típicas, ideais, mais regulares e completas.

Ainda segunda a autora,

[...] uma vez identificados os elementos dessa forma ideal e suas funções específicas, as variações e presença ou ausência nas formas documentais existentes irão revelar a função administrativa dos documentos que manifestam aquelas formas. (DURANTI, 2015, p.197)

Diante dessa perspectiva de análise da forma, Duranti (2015) afirma que os diplomatistas antigos analisavam os documentos sob os seus elementos extrínsecos, que são "aqueles que constituem o aspecto do documento e sua aparência externa" (DURANTI, 2015, p.197) e os elementos intrínsecos, que segundo a autora, eram "aqueles considerados como componentes integrais de sua articulação intelectual” (DURANTI, 2015, p.203).

Ao longo desse período a Diplomática passa a se constituir como uma ciência auxiliar da historiografia, tal como observa Tognoli e Guimarães (2009, p.26), sendo influenciada pela Filologia e a História, pois era "utilizada para verificar a autenticidade documental de documentos medievais enquanto fontes históricas".

Até esse ponto, a Diplomática era compreendida somente como ferramenta para averiguar a autenticidade dos documentos, avançando, com a influência de Theodor Von Sickel, para o estudo crítico e da forma do documento, que foi 
apresentado com rigor científico o método de análise das formas dos documentos, ao passo que Ficker procurou estabelecer a distinção entre o momento da ação e da documentação. (TOGNOLI; GUIMARÃES, 2009)

A partir do século XIX, no seio da Revolução Francesa, como uma extensão da Diplomática, nasce a arquivística enquanto disciplina, sendo apropriada pelos historiadores por meio do estudo dos manuais de Diplomática e das escolas de historiografia e documentação. (TOGNOLI; GUIMARÃES, 2009)

Em 1841 a arquivística passa a ser introduzida nas escolas de historiografia e documentação, sendo promulgado o princípio da proveniência, formalizando-se enquanto disciplina com um conjunto de conhecimentos específicos norteadores ao tratamento dos documentos de arquivo. Porém, ela só consegue ser elevada ao status de disciplina do campo científico por meio da iniciativa de S. Müller, T. Feith e J. Fruin, que publicaram do Manual dos Arquivistas Holandeses, em 1898. Posteriormente outras iniciativas foram realizadas. Em 1922, com a publicação do Manual of Archive Administration, por Hilary Jenkinson e a obra Archivistica, em 1928, por Eugênio Casanova. (TOGNOLI; GUIMARÃES, 2009)

Foi durante e após os anos 30 , do século XX, seja por meio da crise mundial e a explosão documental gerada pela II Guerra Mundial, entre os anos de 1939 e 1945, a arquivística passa de uma ferramenta de resgate histórico para uma ferramenta de auxílio à administração, surgindo nestes momentos o conceito de gestão documental.

Com essa explosão documental decorrente do surgimento de inúmeras funções administrativas os princípios arquivísticos, ainda baseados nos conceitos estipulados pelos famosos manuais, passam a ser reinterpretados, haja vista que as mudanças refletiam na criação dos documentos.

Rondinelli (2011) compreende que a Diplomática e a Arquivologia se relacionam historicamente e quanto ao objeto de estudo, deduzindo que a segunda é uma extensão da primeira e que ambas estudam o documento arquivístico. A Arquivologia, por meio da característica da organicidade, conforme retrata Rondinelli (2011), se relaciona com a Diplomática, resultando em uma completude perfeita, onde a segunda cuida da gênese documental e a primeira trata da classificação dos arquivos, temporalidade, descrição e preservação. 
Foi nessa transição, com a relação entre a diplomática e a arquivística, que o termo Diplomática Arquivística Contemporânea começou a ser adotado por vários autores com base em diversos artigos publicados por Luciana Duranti (RONDINELLI, 2011).

O termo Diplomática Arquivística Contemporânea, porém, segundo Rondinelli (2011), não é aprovado por Luciana Duranti, ao qual a própria autoria esclarece que a disciplina deve ser chamada simplesmente de Diplomática, pois o máximo que poderia ser feito é separar a Diplomática Clássica da Contemporânea, sendo que nessa segunda estaria a Diplomática Digital, ou Especial.

Enquanto a Diplomática se preocupa com a forma do documento, ou seja, "a mesma forma semântica de discurso para a mesma problemática jurídica", tal como elucida Bellotto (2014, p.350), o objeto da tipologia documental é a forma dentro seu contexto funcional e orgânico, onde a espécie documental é utilizada para cumprir funções.

A ampliação no rol de atuação da Diplomática vem, por tanto, com a Tipologia Documental, em direção à gênese documental e do contexto das competências, funções e atividades da entidade geradora. (BELLOTTO, 2014)

Foi nesse momento que a arquivística encontra na Diplomática Clássica um ponto de convergência: o estudo da Tipologia Documental.

Mesmo com a identificação da convergência entre as duas disciplinas, no que tange ao seu objeto de estudo, o documento, só no final do século XX que a Arquivística passa a absorver essa relação com a Diplomática como parte do processo de tratamento documental.

Foi dentro desse contexto que a Diplomática ultrapassa o estudo da espécie documental e torna-se um alicerce para a compreensão da Tipologia Documental, compreendendo o elo existente entre a forma do documento e sua atividade geradora.

Essa lógica orgânica, desde a gênese documental, passa a tornar-se um alicerce fundamental entre a Diplomática Clássica e a Arquivística.

Com essa perspectiva a Diplomática passa a ser chamada de Diplomática Arquivística Contemporânea, e seus estudos iniciam na Itália, com Paola Carucci, sendo a primeira autora "a aplicar a crítica diplomática aos documentos da 
administração pública italiana, redefinindo o conceito de documento diplomático ao incluir aqueles produzidos por uma organização no curso normal de suas funções". (TOGNOLI; GUIMARÃES, 2009, p.30)

Mas foi no Canadá, conforme retrata Tognoli e Guimarães (2009), por meio dos estudos de Luciana Duranti que a disciplina passa a ter um ponto de vista investigativo privilegiado.

\section{A DIPLOMÁTICA CONTEMPORÂNEA E O ESTUDO DA TIPOLOGIA DOCUMENTAL}

Vazquez (1987) compreende a tipologia documental como um atributo em que o documento, originado a partir de uma atividade administrativa, manifesta-se em uma diagramação (fórmula, forma), um determinado formato (sucessão de dados) e conteúdos diferenciados, que algum servirão de elemento para classificalo, descrevê-lo e determina-lo conforme sua respectiva categoria diplomática.

Cortés Alonso (1989) define tipologia documental como sendo aquela que foi gerada em razão de uma determinada atividade que depende das funções e atividades dos homens e das instituições, contendo um número e elementos dispostos da informação.

Heredia Herrera (1991) compreende que a tipologia documental deriva do testemunho de uma determinada atividade do Homem, sendo enquadrado dentro das variadas instituições em que o produzem.

Para alguns teóricos, conforme elucida Rodrigues (2008), a Tipologia Documental é "uma área nova, produto de uma revisão do desenvolvimento e da atualização dos princípios formulados pela diplomática clássica”. (p. 166)

Já Bellotto (2014, p.347) compreende o tipo documental como aqueles que "representam a união que se dá no momento em que se cruzam a função administrativa e o documento-veículo que induza ou que comprove seu cumprimento". A autora, por sua vez, complementa afirmando que o tipo documental é a configuração que a espécie documental, de acordo com as informações que foram produzidas em razão de uma determinada atividade.

Rodrigues (2008) compreende que o estudo das tipologias documentais é imprescindível para as atuais administrações, em virtude da descontrolada 
produção e acumulação de documentos, se agravando ainda mais "com a introdução das tecnologias aplicadas aos processos de trabalho". (p. 176)

Segundo a autora, é um método que se fundamenta no estudo do documento, bem como suas particularidades e especiais características.

A base conceitual do método reside no estreito vínculo existente entre o documento e o contexto que lhe dá origem, o qual se revela da análise de suas características, o que exige um parâmetro normalizado a ser utilizado como ferramenta de identificação. O procedimento tem início pela denominação do documento, utilizando fórmula padronizada para caracterizar a estrutura e o conteúdo do tipo documental. (RODRIGUES, 2008, p.176)

Rodrigues (2008) traz uma visão sobre a tipologia documental e a relação com as funções arquivísticas, por meio de atividades de orientação realizadas no âmbito de um Grupo de Estudo de Identificação, composto por trabalhos de conclusão de cursos de vários autores do Curso de Arquivologia da Universidade Estadual de São Paulo.

Segundo a pesquisa realizada pela autora, os estudos da tipologia documental estariam conectados com a função produção, pois fornecem os parâmetros necessários ao diálogo profissional interdisciplinar, objetivando a simplificação de procedimentos de administração e racionalização de documentos, além de contribuir para a definição de normas para a sua execução e de critérios para a implementação de sistemas de informação.

A tipologia documental, ainda conforme Rodrigues (2008, p.207) também estaria conectada com a função avaliação, reafirmando a natureza específica dos documentos de arquivo, enquanto "elemento de prova, que obedecendo a fórmulas, promove uma única leitura, a da ação que o originou".

A função organização, compreendendo a classificação e a ordenação, com base em Rodrigues (2008), estaria também intrinsecamente conectada com o estudo da tipologia documental, pois é nesse momento em que se compreende, por meio dos próprios tipos documentais, as competências e funções a ele atribuídas, bem como a totalidade das séries documentais produzidas na estrutura interna do fundo. 
E por fim, a autora traz a relação entre a identificação tipológica e a função descrição, evidenciando "a pertinência da identificação aplicada ao tratamento de documentos permanentes, como fundamento para a elaboração de instrumentos de descrição". (RODRIGUES, 2008, p.214)

Semelhante à abordagem de Rodrigues (2008), Bellotto (2014) compreende que também há um vasto campo de aplicação das tipologias documentais, em variados segmentos da arquivística, podendo ser útil tanto nas atividades de arranjo, com os arquivos permanentes, bem como na elaboração dos planos de classificação, com os arquivos correntes. Além disso, a autora compreende que é possível o seu uso na descrição, auxiliando na autenticidade dos conteúdos veiculados em um determinado formato jurídico, bem como nos serviços aos usuários, facilitando, quando corretamente estruturadas e identificadas, o acesso aos documentos certos. E por fim, a autora segue retratando o uso da tipologia documental na avaliação, "porque as tabelas de temporalidade só chegarão e a seu objetivo se baseadas numa identificação das espécies documentais e das respectivas funções, a qual só a tipologia pode proporcionar". (BELLOTTO, 2014, p.349)

Pensando em uma metodologia para a construção da tipologia documental, Bellotto (2014) propõe que se inicie com a análise anterior à própria caracterização da espécie, desde a identificação do gênero documental (textuais, iconográficos, audiovisuais e aqueles legíveis por máquina), perpassando as áreas que estão vinculadas e as categorias (documentos dispositivos, testemunhais e informativos).

A autora ainda segue compreendendo que todo documento precede de uma especialidade, um tempo de guarda e uma causa, sendo necessário que haja três elementos concomitantes, tais como matéria e suporte, meio e tipologia e o conteúdo segunda sua categoria, no sentido do texto normativo, comprobatório e informativo. (BELLOTTO, 2014)

Outros elementos são essenciais à compreensão da tipologia documental, que são considerados elementos constitutivos dos documentos, conforme observa Bellotto (2014), e que a para percepção de Schellenberg (1965) são aqueles considerados elementos físicos e substantivos, ou como classifica Cortés Alonso (1989) os elementos externos e internos. 
Os elementos físicos ou externos são aqueles que dizem respeito à estrutura, à classe física e ao tipo físico, e os elementos substantivos ou internos são os que dizem respeito à substância, ou pelo conteúdo, seja em razão da proveniência e a autoria, seja pelas funções, assuntos e datas.

Bellotto (2014) compreende que há passos para a análise tipológica que são observados a partir de dois pontos de vista, seja ele do ponto de vista da diplomática, seja do ponto de vista arquivístico. Se o foco for diplomático é necessário verificar se a expressão diplomática corresponde à identificação do ato jurídico-administrativo para o qual a análise está se servindo, se o trâmite corresponde à expressão diplomática e se a fusão entre ato e documento segue de forma independente "dos demais componentes de um provável conjunto arquivístico" (BELLOTTO, 2014, p.359).

Se o foco for arquivístico aí será necessário atentar para as questões relacionadas ao fluxo da informação e do documento, considerando aspectos como: se há interação homogênea entre a produção dos atos e os conjuntos; se há uma constância entre os procedimentos de gestão e a produção isolada de documentos isolados; se os prazos de guarda das mesmas tipologias de um mesmo conjunto são uniformes; se os conjuntos não estão dispersos, em razão da constituição dos fundos e suas demais subdivisões; e se há frequência de informação habitual nos documentos constitutivos da série.

Dessa forma, considerando o universo de trabalho da Diplomática Contemporânea, que tem como foco o estudo das tipologias documentais, enquanto reflexo da união entre a espécie documental e a atividade geradora, passamos a realizar a reflexão sobre a relação entre a diplomática e a função matricial da arquivística, a classificação.

\section{A DIPLOMÁTICA E A CLASSIFICAÇÃO DE DOCUMENTOS ARQUIVÍSTICOS}

Durante muito tempo o conceito de classificação na Arquivística, segundo Sousa (2004), foi moldado e fundamentado em aspectos artificiais sem estarem ligados ao um saber científico, a um método, apesar do conceito não ser estranho à literatura arquivística. 
A classificação, conforme retrata Sousa (2004) aparece na literatura desde o século XVII, com o surgimento dos primeiros manuais com normas escritas e os primeiros elementos de uma doutrina nessa área são encontrados na obra $D e R e$ Diplomática, do então Jean Mabillon, em 1861.

A obra De Re Diplomática propôs um "método sistemático de investigação para determinar os fatos e eventos nos quais os documentos se inseriam e não noções sobre organização ou descrição". (SOUSA, 2004, p.13)

Classificação, segundo Schellemberg (1959, p.26) compreende "a criação de um sistema de classes dispostas em determinada ordem, segundo a qual se possam agrupar os documentos e a localização dos documentos nos respectivos lugares em tal sistema". Ainda segundo o autor o termo deve ser somente aplicado ao processo que trata da ordenação dos documentos de caráter corrente e não àqueles considerados "não correntes" e que foram transferidos para um arquivo.

O Conselho Internacional de Arquivos (1984) define a classificação enquanto aquela ação de analisar e determinar o assunto de um determinado documento, escolhendo a categoria do assunto ao que ele pertença, atribuindo-Ihe código para fins de recuperação futura.

Heredia Herrera (1991) compreendia o termo Classificar enquanto "separar ou dividir um conjunto de elementos estabelecendo classes ou grupos" (p. 263), distinguindo a classificação, em sua totalidade, do processo de ordenação, que era realizada sobre os documentos de cada série.

Já Couture (1999) descreve a classificação enquanto processo intelectual de identificação e de agrupamento, de forma sistêmica, de elementos que se assemelham, com base em suas características comuns "que podem ser seguidamente objeto de uma diferenciação se a quantidade a exige." (p. 18)

Gonçalves (1998) relembra que a operacionalização do trabalho de classificação, ou seja, o procedimento técnico de execução dessa atividade, alcança, por tanto, os tipos documentais, pois é neste momento em que eles são identificados e articulados entre si. Ou seja, o processo de trabalho da classificação é compreender as tipologias documentais e a ligação que há entre elas, em razão daquilo que as gera, que é a atividade, no âmbito orgânico. 
Bom, para darmos continuidade à reflexão é importante e necessário recordarmos o conceito de arquivo, haja vista que a classificação só consegue ter o seu significado para o âmbito da Arquivística se bem compreendido esse conceito.

Segundo Jenkinson (1922) arquivo é um conjunto de documentos, que independente de sua natureza, instituição ou pessoa, foi reunido de forma natural e organicamente em razão das funções e atividades.

Schellenberg (2006) já traz o conceito com base na visão da história, enquanto documentos que permanecerão guardados permanentemente, mas que também foram produzidos e acumulados pela instituição, seja ela pública ou privada, e que foram avaliados dessa forma para fins de referência ou de investigação.

Lopez (2005) contrapõe a visão dos historiadores quando afirma que os documentos são frutos de uma vontade administrativa, sendo produzidos e preservados por razões alheias às suas atividades.

Se, por tanto, os documentos são reflexos de uma atividade geradora e a classificação lidará justamente com esse reflexo, a tipologia documental, voltamos a observar sobre o objeto de estudo da Diplomática Contemporânea, que é a Tipologia Documental.

Segundo Heredia Herrera (1991, p.135), "os tipos documentais derivam dos testemunhos das diversas atividades do Homem, enquadrados dentro das também variadas instituições de onde se produzem".

Enquanto que a diplomática contemporânea compreende a tipologia documental como parte do estudo do documento, a classificação compreende-a enquanto reflexo das atividades desenvolvidas por uma determinada organização, sendo inseparável a compreensão de ambas as vertentes.

Considerando a relação existente entre a Diplomática Contemporânea e a classificação de documentos de arquivo, sigamos para o universo dos documentos digitais, realizando a reflexão sobre a autenticidade no meio digital.

\section{OS DOCUMENTOS ARQUIVÍSTICOS DIGITAIS E A DIPLOMÁTICA}

O CONARQ (2005) define documento digital como os codificados em dígitos binários, que só são acessíveis por meio de sistemas computacionais, enquanto 
que o analógico não, apesar dos dois tipos de suportes serem físicos.

Innarelli (2015) ao tratar o documento arquivístico digital recorda sobre o aspecto intrínseco ao próprio documento arquivístico, reforçando a ideia apresentada pelo Arquivo Nacional de que mesmo sendo digital terá que atender às mesmas exigências atribuídas ao documento em suporte analógico quanto ao seu próprio funcionamento.

Segundo o e-ARQ Brasil (CONARQ, 2011, p.9) o documento arquivístico digital "é um documento digital que é tratado e gerenciado como um documento arquivístico, ou seja, incorporado ao sistema de arquivos." O e-ARQ Brasil vem, em âmbito estratégico e operacional propor requisitos para que os sistemas de informação brasileiros, tanto no que se refere ao Poder Público, quanto para o uso da esfera privada, estejam em consonância com aspectos da gestão arquivística de documentos.

\begin{abstract}
Este trabalho foi desenvolvido considerando a existência de um importante legado de documentos em formato digital, que vem sendo tratado por especialistas de diversas áreas, entre as quais a arquivologia e tecnologia da informação. Esses especialistas conceituam 0 documento arquivístico e 0 documento arquivístico digital para poder analisar e propor soluções que enfrentam os desafios trazidos por este formato. (CONARQ, 2011, p.9)
\end{abstract}

Algumas características são primordiais para a análise do documento arquivístico digital, tais como a organicidade, unicidade, confiabilidade, acessibilidade e autenticidade, de tal forma que seja possível pautar, de forma segura, a gestão da preservação desses acervos. (INNARELLI, 2015)

A organicidade, segundo o e-ARQ Brasil, é característica básica de um documento arquivístico em razão da relação que mantém com os demais documentos de uma organização, pois seu elo de ligação uns aos outros é materializado no plano de classificação, apresentando seu contexto de interação. Essa interação é fundamental e deve ser mantida entre os documentos arquivísticos.

A unicidade é a próxima característica observada pelo CONARQ (2011) quando recorda que um documento arquivístico é único no conjunto documental ao 
qual pertence, mesmo que existam múltiplas cópias em um ou mais grupos de documentos, pois cada uma delas é única em seu respectivo lugar, aonde o conjunto dessas relações com os demais documentos desse agrupamento é único.

Todo documento arquivístico deve ser confiável, ou seja, que tenha a capacidade de sustentar os fatos que atesta, sendo atribuída no momento em que o documento é produzido em razão da veracidade do seu conteúdo. Aspectos relacionados à completeza (presença de todos os elementos intrínsecos e extrínsecos exigidos pela organização produtora e pelo sistema jurídicoadministrativo ao qual pertence) e seus procedimentos bem controlados. (CONARQ, 2011)

Talvez o maior objetivo de um documento arquivístico é estar acessível e para o universo do campo digital não poderia ser diferente. Ou melhor, é um dos aspectos mais contundentes e o porquê da criação de um documento arquivístico digital. O e-ARQ Brasil (2011) traz o aspecto em que o documento arquivístico digital só é o que diz ser enquanto puder ser localizado, recuperado, apresentado e interpretado, sendo como exigência de qualquer programa de gestão arquivística a transmissão de documentos para outros sistemas sem que haja perda de informação e de funcionalidade.

Atualmente o que mais se discorre quanto aos documentos arquivísticos digitais é a sua autenticidade. Autenticidade, segundo o Conselho Nacional de Arquivos (CONARQ), diz respeito à "qualidade de um documento ser exatamente aquele que foi produzido, não tendo sofrido alteração, corrompimento e adulteração." (CONARQ, 2012, p.2)

Para tanto, ela será composta de identidade e integridade, sendo que a primeira corresponderá ao "conjunto de atributos de um documento arquivístico que o caracterizam como único e o diferenciam de outros documentos arquivísticos" (CONARQ, 2012, p.2) e o segundo correspondente à "capacidade de um documento arquivístico transmitir exatamente a mensagem que levou à sua produção" (CONARQ, 2012, p.2).

A Diplomática Clássica, com o recurso de outras áreas do conhecimento humano, tais como a Paleografia, a Sigilografia e a História, buscava o reconhecimento da autenticidade dos documentos, o que foi bastante evidenciado 
durante o século XVII e XVIII.

Ao lado da Arquivística moderna, a Diplomática Contemporânea, durante o período da era digital passa a resgatar noções e preceitos básicos que passarão a auxiliar a autenticidade de documentos digitais.

Segundo o CONARQ (2012), o reconhecimento da autenticidade de documentos arquivísticos está relacionado com três aspectos essenciais: o aspecto legal, o diplomático e o histórico.

Para que o documento possa ser legalmente autêntico é necessário que ele tenha dado testemunho sobre si mesmo, em razão da intervenção, seja durante ou após a sua produção, por uma autoridade pública representativa, de tal forma que possibilite a garantia de sua genuinidade. (CONARQ, 2012)

Mas para ele ser diplomaticamente autêntico é necessário que ele tenha sido "escrito de acordo com a prática do tempo e do lugar indicados no texto e assinados pela pessoa (ou pessoas) competente para produzi-los." (CONARQ, 2012, p.3)

E por fim, para que seja historicamente autêntico ele tem que ter atestado algum evento que de fato aconteceu ou que as informações sejam verdadeiras. (CONARQ. 2012)

O CONARQ (2012) afirma que os três aspectos relativos à autenticidade de um documento são independentes um do outro, pois mesmo se for atestada a autenticidade diplomática e histórica de um documento e não for atestado por uma autoridade ele será considerado legalmente inautêntico.

Esses aspectos são fortalecidos pelo CONARQ (2012), quando ele observa a relação entre eles:

[...] observa-se uma relação entre o aspecto histórico da autenticidade e o conceito diplomático de confiabilidade no sentido de que ambos se referem à veracidade do conteúdo do documento. Já no que tange ao ponto de vista da diplomática, a autenticidade se refere a não alteração do documento após a sua produção, mesmo que o conteúdo não seja verdadeiro. (CONARQ, 2012, p.4)

Partindo-se desses pressupostos, o CONARQ compreende que haverá presunção de autenticidade de um documento arquivístico digital se for analisada alguns aspectos essenciais: a forma, o conteúdo, ambiente de produção, 
manutenção/ uso e preservação do documento.

A Diplomática Clássica já evidenciava os aspectos relacionados à forma e conteúdo do documento de forma bastante profunda e rígida, tal como observa Duranti (2015, p.208), quando descreve os elementos extrínsecos e intrínsecos da forma documental, que antigamente foram identificados pelos diplomatistas por meio de "um grande número de documentos produzidos em tempos e jurisdições diferentes, por vários tipos de criadores de documentos para fins diversos."

Esse estudo da forma e do conteúdo foi essencial para que diante a evolução dos suportes da informação atualmente fosse possível fundamentar 0 trabalho de autenticidade dos documentos digitais.

O ambiente de produção do documento digital, tal como descreve o CONARQ (2012), compreende os procedimentos de controle (quem produz, mantém, usa, preserva os documentos arquivísticos digitais e como essas ações serão realizadas), o sistema informatizado (devendo-se ter diretrizes que permitam a inclusão de trilhas de auditoria, controle de acesso de usuários, dentre outros) e o próprio produtor e/ou custodiador dos documentos (sendo imprescindível que tenha reputação idônea, capacidade e conhecimento específico para gerenciar os documentos, bem como inspirar confiança dos usuários).

O último ponto analisado pelo CONARQ (2012) é sobre as técnicas de autenticação, advertindo que dependerão da tecnologia empregada, tal como a assinatura digital, que declaram a autenticidade de um documento digital em um dado momento.

Atualmente é muito comum as organizações, sejam elas públicas ou privadas, buscarem na assinatura digital um meio de dar autenticidade permanente aos documentos, mas o próprio CONARQ adverte sobre o perigo da ação ao longo do tempo.

A assinatura digital é resultado de um cálculo matemático que envolve a cadeira de bits do documento e a chave da assinatura digital. Se a cadeira de bits for alterada, por motivo de corrompimento, adulteração ou conversão, a assinatura não corresponderá mais a essa nova cadeira de bits e não poderá mais garantir a autenticidade do documento. Isto porque, embora o documento conceitual seja o mesmo, passará a estar relacionado a uma nova cadeira de bits, que não tem mais a assinatura. Desta forma, a assinatura digital garante somente a 
integridade da cadeira de bits original, mas não a do documento conceitual ao longo do tempo. (CONARQ, 2012, p. $5-6)$

A autenticidade do documento, por tanto, segundo o CONARQ (2012), não é garantida exclusivamente em função da assinatura digital, pois a longo prazo será essencial outros tipos de procedimentos de gestão para que seja possível manter a autenticidade, tais como os metadados inerentes ao processo de natural de uso e futuras conversões.

\section{CONSIDERAÇÕES FINAIS}

A partir das reflexões realizadas pode-se observar que o estudo da Diplomática perpassou os tempos na busca pela autenticidade dos documentos, a partir da forma em que são constituídos, seja diante a análise das características intrínsecas, seja pela compreensão dos seus aspectos extrínsecos, até o momento em que no relacionamento com outras disciplinas ampliou seu estudo para a Tipologia Documental.

Mas foi ao lado da Arquivística que passou a compreender os documentos enquanto reflexos de uma determinada atividade organizacional, quando passou a perceber que durante a gênese documental, no momento em que o documento era produzido, a sua forma, ou a espécie do documento, aliava-se à atividade geradora, para constituir a Tipologia Documental.

Dessa percepção, e durante o mesmo período de tempo, a Classificação surge como aliada à Diplomática, dando a ênfase necessária ao trabalho de análise documental, fundamentando consideravelmente os aspectos do tratamento documental.

Com a era digital a Diplomática reacende seu aspecto inicial dando a substância necessária ao trabalho de atribuição da autenticidade aos documentos arquivísticos digitais, discutindo e estendendo os aspectos inerentes à análise da forma e conteúdo do documento para o ambiente de produção, manutenção/ uso e preservação do documento. 


\section{REFERÊNCIAS}

BELLOTTO, H. L. Arquivo: estudos e reflexões. Belo Horizonte: Ed. da UFMG, 2014.

CONSELHO INTERNACIONAL DE ARQUIVOS. Dicionário de terminologia arquivística. Paris: CIA, 1984.

CONSELHO NACIONAL DE ARQUIVOS (BRASIL). Carta para preservação do patrimônio arquivístico digital. Rio de Janeiro: Arquivo Nacional, 2005.

e-Arq Brasil: modelo de Requisitos para Sistemas Informatizados de Gestão Arquivística de Documentos. Versão 1.1. - Rio de Janeiro: Arquivo Nacional, 2011.

. Diretrizes para a presunção de autenticidade de documentos arquivísticos digitais. Rio de Janeiro: Arquivo Nacional, 2012.

CORTÉS ALONSO, V. Principios y tecnicas archivisticas. In: Manual de archivos municipales. Madrid: ANABAD, 1989.

COUTURE, C. Les functions de L'Archivistique contemporaine. Quebec: Presses de l' Université du Québec, 1999.

DURANTI, L. Diplomática: novos usos para uma antiga ciência (parte V). Acervo, Rio de Janeiro, v. 28, n.1, p. 196-215, jan./jun. 2015.

HEREDIA HERRERA, A. Archivistica general: Teoria y practica, Sevilha: Diputación de Sevilha, 1991.

INNARELLI, H. C. Gestão de preservação de documentos arquivísticos digitais: proposta de um modelo conceitual. 2015. Teste (Doutorado) - Programa de Pós-Graduação em Ciências da Informação - Escola de Comunicações e Artes, Universidade de São Paulo, São Paulo.

JENKINSON, H. A Manual of Archive Administration. Oxford, Clarendon Press, Part III; "Modern Archives", 1922.

LOPEZ, A. P. A. História e arquivos: interfaces. In: Introdução ao estudo da história - Formação de professores (EAD), n.ำ27, Maringá: EDUEM, 2005.

RODRIGUES, A. C. Diplomática contemporânea: como fundamento metodológico da identificação de tipologia documental em arquivos. 2008. Tese (Doutorado em História Social) - Departamento de História, Universidade de São Paulo, São Paulo. 
ROGERS, C. A literature review of authenticity of records in digital systems: from 'machine-readable' to records in the cloud. Acervo, Rio de Janeiro, v. 29, n. 2, p. 16-44, jul./dez. 2016.

RONDINELLI, R. C. O Conceito de documento arquivístico frente à realidade digital: uma revisitação necessária. 2011. Tese (Doutorado em Ciência da Informação) - Instituto de Arte e Comunicação Social, Instituto Brasileiro em Ciência e Tecnologia, Universidade Federal Fluminense, Rio de Janeiro.

SCHELENBERG, T. R. Manual de arquivos. Rio de Janeiro: Arquivo Nacional, 1959.

. Caracteres dos documentos. Documentos públicos e privados: arranjo e descrição. Trad. Manoel A. Wanderley. Rio de Janeiro: Arquivo Nacional, 1963.

Arquivos Modernos. Princípios e técnicas. Tradução de Nilza Teixeira Soares. 6⿳⺈冂大 Ed. Rio de Janeiro: FGV, 2006.

SOUSA, R. T. B. Classificação em arquivística: trajetória e apropriação de um conceito. 2004. Tese (doutorado) - Programa de Pós-Graduação em História Social, do Departamento de História da Faculdade de Filosofia, Letras e Ciências Humanas da Universidade de São Paulo, São Paulo.

TOGNOLI, N. B.; GUIMARÃES, J.A.C. A Diplomática Contemporânea como base metodológica para a organização do conhecimento arquivístico: perspectivas de inovação a partir das idéias de Luciana Duranti. In: ROMERO, N. L. (Ed.; Org.). Nuevas perspectivas para la difusion y organización del conocimiento. Valência: Universidad Politécnica de Valencia, v. 1, p. 38-47, 2009.

VAZQUEZ, M. Reflexiones sobre el termino tipo documental. In: De archivos y archivistas: homenaje a Aurellio Tanodi. Washington: OEA, 1987, p. 177-185.

\title{
CONTEMPORARY DIPLOMATIC: REFLECTIONS ON THEIR APPLICABILITY IN THE DIGITAL AGE
}

\begin{abstract}
Introduction: Over a long time, the Diplomatic contributed significantly to the identification of the authenticity of the documents, expanding its acting role when he was influenced by other disciplines such as modern archiving, which leveraged its object of study, showing the deep connection between species and its generating activity. Objective: This study aims to conduct reflections on the evolution of the
\end{abstract}


Diplomatic Classical to Contemporary Diplomacy, the relationship between this discipline and Document Classification and its impact on the digital age, the constitution of the authenticity process of digital archival documents. Methodology: The nature of research is classified as basic, how to approach is classified as qualitative, the research objective classified as exploratory, involving literature review regarding the diplomatic in its relationship with the archival and employability in the digital age. Results: After searching, it is understood that the Diplomatic permeates time, on aspects of study of the documentary kind, yet its relationship with modern archiving, as is the study of the universe of the Document Type, identifying with Classification as matrix function of modern archiving, and using the analysis features of authenticity in the digital environment. Conclusion: It is evident that there is an intrinsic relationship between the Diplomatic in his contemporary perspective, with modern archiving, both in understanding the aspects of documentary typology, as an essential tool in the analysis of authenticity in the digital environment.

Descriptors: Diplomatic Contemporary . Document Type . Classification. Authenticity. Digital archival documents .

\title{
LA DIPLOMÁTICA CONTEMPORÁNEA: REFLEXIONES SOBRE SU APLICABILIDAD EN LA ERA DIGITAL
}

\begin{abstract}
RESUMEN
Introducción: Durante mucho tiempo, la diplomática contribuyó significativamente a la identificación de la autenticidad de los documentos, ampliando su papel como actor cuando él fue influenciado por otras disciplinas como el archivado moderna, que aprovechó su objeto de estudio, que muestra la conexión profunda entre las especies y su actividad de generación. Objetivo: El presente estudio tiene como objetivo llevar a cabo reflexiones sobre la evolución de la clásica Diplomática a la Diplomática contemporánea, la relación entre esta disciplina y clasificación de documentos y su impacto en la era digital, la constitución del proceso de autenticidad de los documentos de archivo digitales. Metodología: La naturaleza de la investigación se clasifica como básico, la forma de abordar se clasifica como cualitativa, el objetivo de la investigación clasificada como exploratoria, que implica revisión de la literatura en relación con el diplomático en su relación con el archivo y la empleabilidad en la era digital. Resultados: Después de buscar, se entiende que la impregna Diplomática tiempo, sobre los aspectos del estudio de la clase documental, sin embargo, su relación con el archivado moderna, como es el estudio del universo del tipo de documento, con la identificación de la clasificación como función de la matriz de archivado moderna, y el uso de las funciones de análisis de autenticidad en el entorno digital. Conclusión: Es evidente que existe una relación intrínseca entre la Diplomática en su perspectiva contemporánea, con el archivado moderna, tanto en la comprensión de los aspectos de la tipología documental, como una herramienta esencial en el análisis de la autenticidad en el entorno digital.
\end{abstract}

Descriptores: Diplomática contemporáneo. Tipo de documento. Clasificación. Autenticidad. Documentos de archivo digitales. 